\title{
Inflammatory bowel disease in ankylosing spondylitis
}

M. I. V. JAYSON, P. R. SALMON, AND W. J. HARRISON

From the Royal National Hospital for Rheumatic Diseases, Bath, and the Departments of Medicine and Pathology, University of Bristol

SUMMARY Routine detailed gastroenterological investigations were performed in a series of 47 ankylosing spondylitics. Evidence of chronic inflammatory bowel disease was found in eight patients, a prevalence of $17 \%$. Unsuspected bowel disease was found in the absence of symptoms in three of these patients.

The association between ulcerative colitis and ankylosing spondylitis has been well documented. Received for publication 6 August 1969.
Court-Brown and Doll (1957) studied a population of 13,352 ankylosing spondylitics and found 13 deaths from colitis instead of the expected

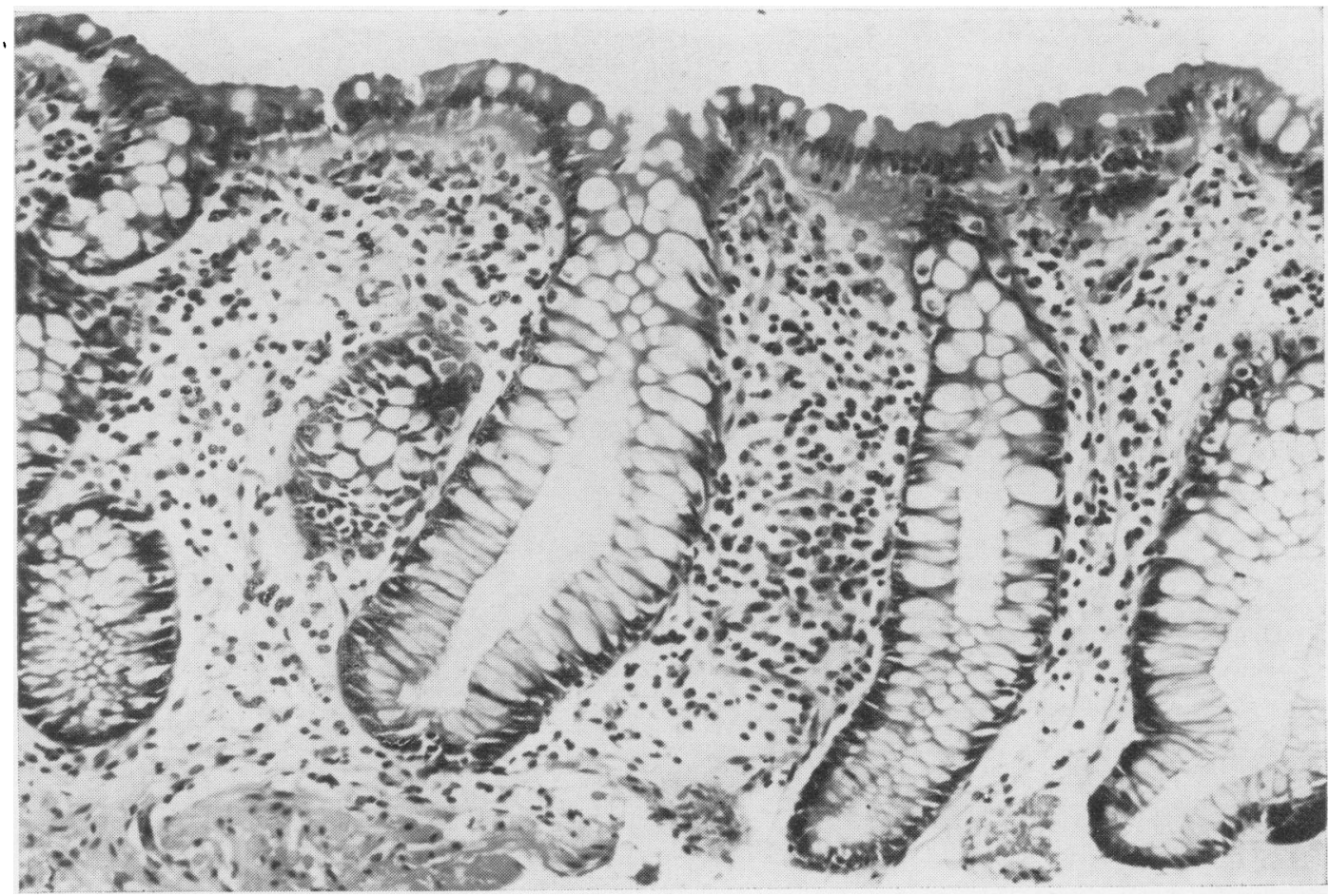

Fig. 1 Rectal biopsy showing excessive numbers of plasma cells in the lamina propria. Haematoxylin and eosin, $\times 200$. 


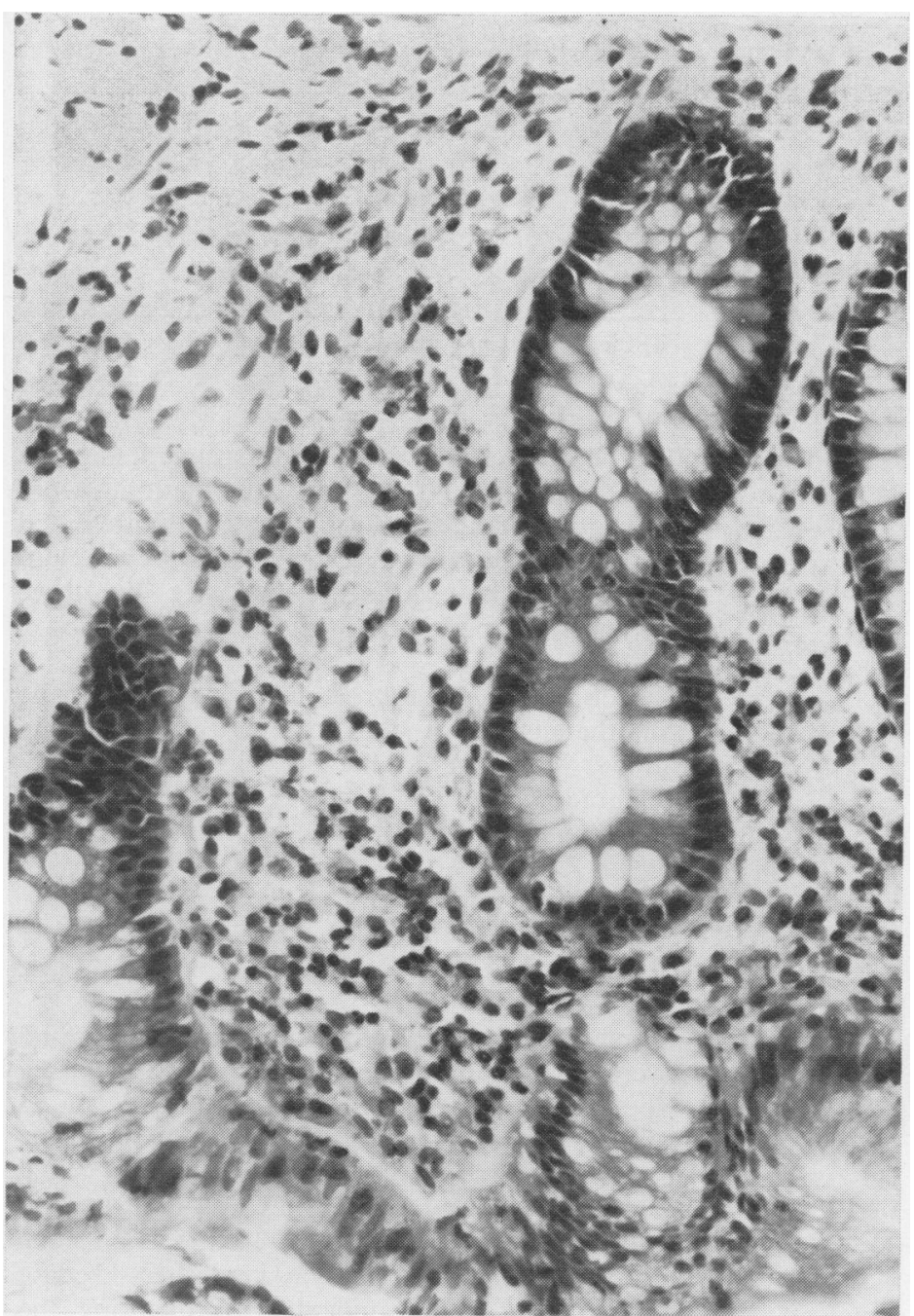

Fig. 2 Rectal biopsy. There is an excess of cells in the lamina propria; these include neutrophil polymorphs as well as eosinophils, plasma cells, and lymphocytes. Haematoxylin and eosin, $\times 360$.

incidence of 0.65 (personal communication to McBride, King, Baikie, Crean, and Sircus, 1963; Wright and Watkinson, 1965). In other series of patients with colitis the prevalence of ankylosing spondylitis has been reported as up to $6 \%$ (Fernandez-Herlihy, 1959; Ford and Vallis, 1959; Zvaifler and Martel, 1960; McEwen, Lingg, Kirsner, and Spencer, 1962; Rotstein, Entel, and Zeviner, 1963; McBride et al, 1963; Wright and Watkinson. 1965) and of sacro-iliitis as up to $17.9 \%$ (Wright, Lumsden, Luntz, Sevel, and Truelove, 1965; Wright and Watkinson, 1965).

Conversely, in studies of ulcerative colitis in ankylosing spondylitics (Romanus, 1953; Steinberg and Storey, 1957; Wilkinson and Bywaters, 1958; McBride et al, 1963; Serre and Simon,
1964), the highest incidence recorded was $3.9 \%$. However, studies of the large intestine were confined to patients with bowel symptoms and, therefore, might easily have missed patients with subclinical ulcerative colitis (Kiefer and Gialanella, 1960; Dick, Holt, and Dalton, 1966).

In an earlier series (Jayson and Bouchier, 1968) in which ankylosing spondylitics were routinely examined for evidence of ulcerative colitis, a prevalence of $18 \%$ was obtained. A larger and more detailed study, including histological examination of the rectal mucosa, has been completed.

\section{Clinical Material and Methods}

All patients in whom a diagnosis of ankylosing spondylitis had been recorded between 1958 and 1968 at the Royal National Hospital for Rheumatic Diseases were circulated, and asked to attend for interview. After full explanations those attending agreed to undergo further investigations. All patients underwent a complete clinical examination with special reference to the manifestations of ankylosing spondylitis. Venesection was performed on all patients for the erythrocyte sedimentation rate, haemoglobin, white cell count, and sheep agglutination test titre. Radiographs were taken of the spine except in those in whom such radiographs had been obtained within the previous two years and these were examined for erosions, sclerosis, and fusion of the sacro-iliac joints. and for involvement of the lumbar spine.

Diagnosis of ankylosing spondylitis was based on the Rome criteria (Kellgren, 1962). Details of all treatments, with particular reference to corticosteroids and irradiation, were recorded.

A full gastrointestinal history was taken and particular attention was paid to weight loss, abdominal pain, frequency of bowel motion, diarrhoea, bleeding, and other rectal complaints. Enquiry was made into the family history with particular regard to rheumatological and gastrointestinal disease. A careful abdominal examination was performed in each subject and this was followed by proctosigmoidoscopy without bowel preparation. The Sim's position was used, as patients with a stiff spine find it difficult to tolerate the knee-chest position. The mucosa was examined for contact bleeding, granularity, friability, vascular pattern, oedema, and ulceration, and diagnosis was based upon the discontinuous variable features defined by Baron, Connell, and Lennard-Jones (1964), namely, bleeding to light touch at initial inspection, and spontaneous bleeding ahead of the instrument on an abnormal mucosa. A diagnosis of proctocolitis was not based upon poorly definable criteria such as mucosal colour and presence of excess mucus alone. Biopsy was taken from a rectal valve at approximately $10 \mathrm{~cm}$ from the anal margin. 


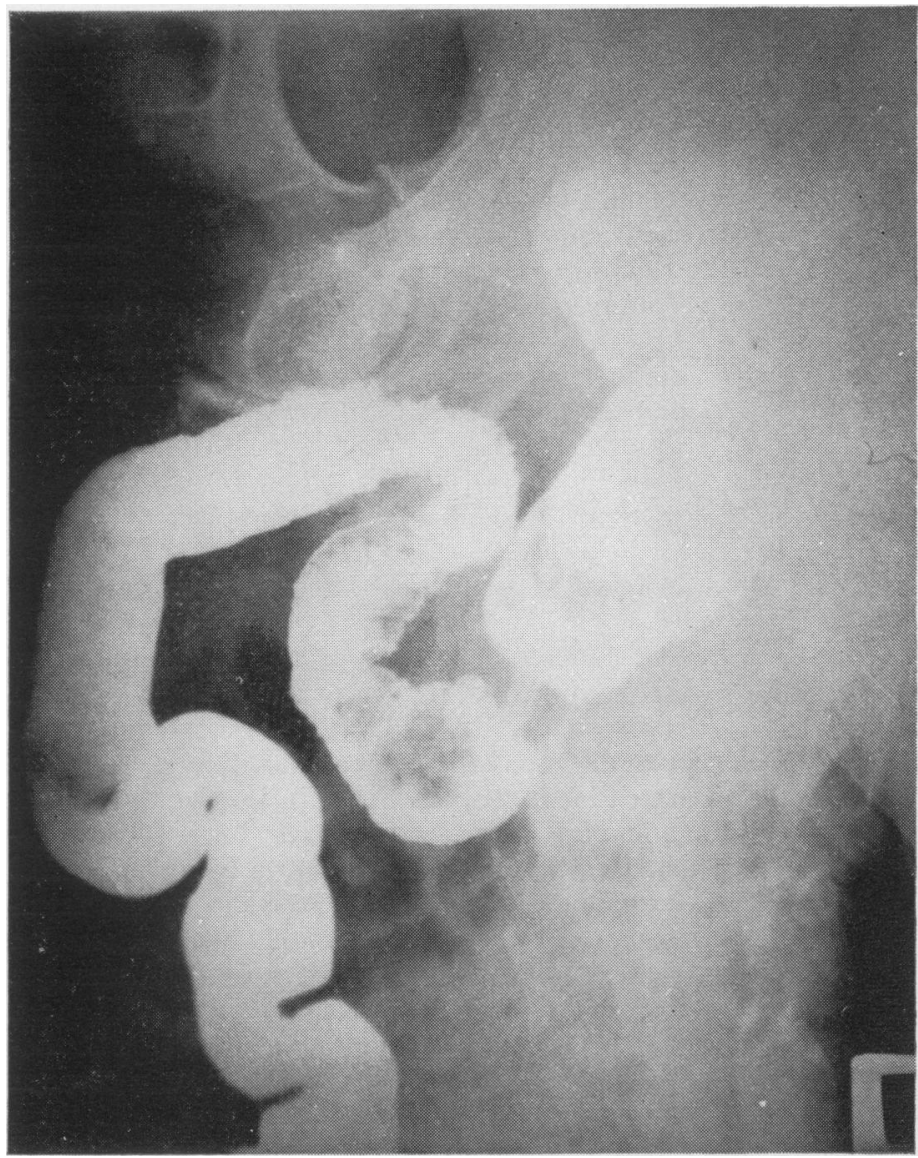

Fig. 3 Barium enema. There is a persistent irregularity of the sigmoid mucosa.

The biopsy specimens were fixed in $10 \%$ formol saline, processed, and embedded in paraffin wax. Sections were taken at two levels in each block, stained with haematoxylin and eosin, and randomly mixed with sections of rectal biopsies obtained from 12 normal control subjects. They were then coded and examined without knowledge of their identity by a histopathologist with a special interest in colitis. All sections were examined on five separate occasions during the course of several months. The results were recorded independently on each occasion without reference to previous clinical, sigmoidoscopic, or radiological findings. A diagnosis of colitis was made only on slides selected as being abnormal on all five examinations (Figs. 1 and 2).

A barium enema examination was requested in all subjects. The diagnostic criteria were those defined by Fennessy, Sparberg, and Kirsner (1966) which included granularity of the mucosal pattern on air contrast films, fine serrations or spiculation of the mucosal border, loss of haustral folds, rigidity of the colon, and widening

\begin{tabular}{lllll}
\hline Patient & History & Sigmoidoscopy & $\begin{array}{l}\text { Rectal } \\
\text { Biopsy }\end{array}$ & $\begin{array}{l}\text { Barium } \\
\text { Enema }\end{array}$ \\
\hline $\mathbf{1}$ & - & - & - & + \\
$\mathbf{2}$ & - & + & - & - \\
$\mathbf{3}$ & + & - & + & - \\
$\mathbf{4}$ & + & + & + & + \\
$\mathbf{5}$ & + & + & + & - \\
$\mathbf{6}$ & + & + & + & + \\
$\mathbf{7}$ & - & - & + & - \\
$\mathbf{8}$ & + & + & + & - \\
\hline
\end{tabular}

Table I Patients with inflammatory bowel disease

of the presacral space. These features had to be consistent throughout the examination. More advanced changes of ulcerative colitis presented little difficulty in diagnosis. All the barium enemas were examined separately by three physicians experienced in the diagnosis of bowel disease.

The diagnosis of proctocolitis was not made on the history of diarrhoea or rectal bleeding alone, but required the presence of a definite sigmoidoscopic, histological, or radiological abnormality.

\section{Results}

Forty-eight of $\mathbf{8 1}$ spondylitics requested to attend were investigated. The diagnosis of ankylosing spondylitis was confirmed in 47 , the remaining subject having rheumatoid arthritis involving the spine. The large bowel investigations were carried out in all 47 spondylitics except that barium enemas were not obtained in 11 patients, in some due to a failure to attend, and in others because the subjects found difficulty in tolerating the examination due to a stiff spine.

A diagnosis of proctocolitis was made in eight patients and details of the investigations in these patients are shown in Table I. Seven of these were thought to have ulcerative colitis and one Crohn's disease.

A history of diarrhoea was obtained in only five of these patients and an abnormal sigmoidoscopy was found in five. Five had abnormal rectal biopsies (Figs. 1 and 2). An abnormal barium enema was found in two subjects (Fig. 3), and, in a further case, a barium follow-through examination showed the changes of Crohn's disease in the terminal ileum (Figs. 4 and 5)

Multiple statistical comparisons were made between the patients with and without inflammatory bowel disease but there were no significant associations with the development of colitis (Table II).

\section{Discussion}

The diagnosis of ulcerative colitis can present 


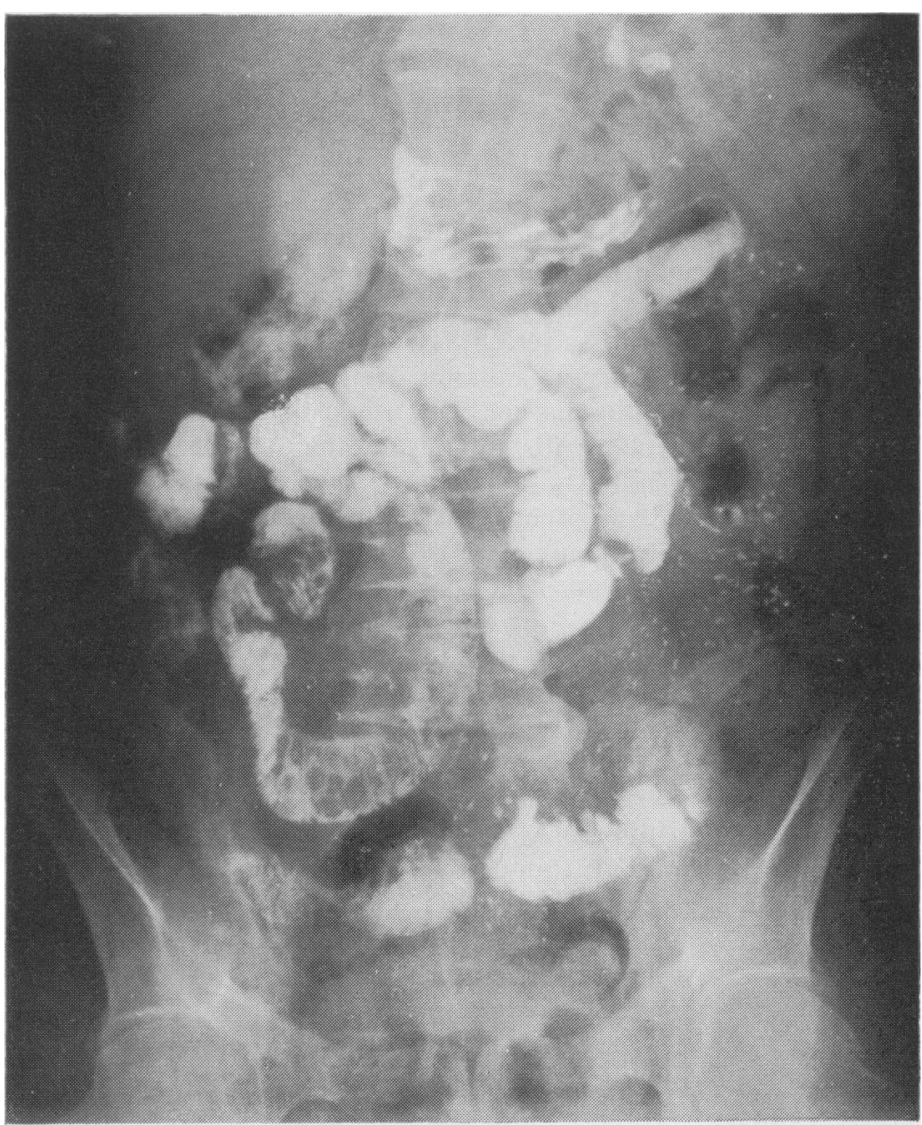

Fig. 4 Barium meal follow-through. A three-hour film showing multiple filling defects in the lower jejunum. The proximal jejunum shows abnormal flocculation.

\begin{tabular}{|c|c|c|c|c|}
\hline & \multicolumn{2}{|l|}{ Normal Bowel } & \multicolumn{2}{|c|}{ Ulcerative Colitis } \\
\hline & Number & Percentage & Number & Percentage \\
\hline Patients & 39 & $83 \cdot 0$ & 8 & $17 \cdot 0$ \\
\hline Mean age (yr) & $42 \cdot 7 \pm 12 \cdot 7$ & & $37 \cdot 3 \pm 14 \cdot 1$ & \\
\hline Male & 33 & $84 \cdot 6$ & 7 & $87 \cdot 5$ \\
\hline Female & 6 & $15 \cdot 4$ & 1 & $12 \cdot 5$ \\
\hline \multicolumn{5}{|l|}{ History of ankylosing } \\
\hline $\begin{array}{l}\text { sponaylitis (yr) } \\
\text { Chest expansion (in.) }\end{array}$ & $\begin{array}{r}13.7 \pm 23.9 \\
1.61 \pm 0.87\end{array}$ & & $\begin{array}{r}16 \cdot 1 \pm 14.7 \\
1 \cdot 30 \pm 1 \cdot 70\end{array}$ & \\
\hline \multirow{2}{*}{\multicolumn{5}{|c|}{$\begin{array}{l}\text { Large peripheral joint } \\
\text { involvement }\end{array}$}} \\
\hline & 22 & $56 \cdot 4$ & 3 & $37 \cdot 5$ \\
\hline \multicolumn{5}{|l|}{ Small peripheral joint } \\
\hline involvement & 4 & $10 \cdot 3$ & $\mathbf{0}$ & 0 \\
\hline Iritis & 12 & $30 \cdot 8$ & 4 & 50.0 \\
\hline Aortic incompetence & 2 & $5 \cdot 1$ & 0 & 0 \\
\hline Psoriasis & 2 & $5 \cdot 1$ & 2 & $25 \cdot 0$ \\
\hline Salicylates & 29 & $74 \cdot 4$ & $\overline{5}$ & $62 \cdot 5$ \\
\hline Phenylbutazone & 23 & $59 \cdot 0$ & 6 & $75 \cdot 0$ \\
\hline Corticosteroids & 10 & $25 \cdot 6$ & 4 & $50 \cdot 0$ \\
\hline Radiotherapy & 21 & $53 \cdot 8$ & 5 & $62 \cdot 5$ \\
\hline \multicolumn{5}{|l|}{ History of urogenital } \\
\hline tract infection & 5 & $12 \cdot 8$ & 2 & $25 \cdot 0$ \\
\hline \multicolumn{5}{|l|}{ Sheep cell agglutination } \\
\hline titre $>1: 32$ & 4 & $10 \cdot 3$ & $\mathbf{0}$ & $\mathbf{0}$ \\
\hline
\end{tabular}

Table II Comparison of colitic and non-colitic patients considerable difficulties. Bywaters and Ansell (1958), Kiefer and Gialanella (1960), Dick et al (1966), and Jayson and Bouchier (1968) have described patients with the changes of ulcerative colitis on investigation in the complete absence of bowel symptoms. McBride et al (1963) found two symptom-free patients with small bowel disease on barium follow-through examination. Because of these findings it would seem that the true prevalence of inflammatory bowel disease may be much higher than that found in studies restricted to patients with significant bowel symptoms. It is, therefore, necessary to examine all cases with ankylosing spondylitis for evidence of bowel disease.

For the purpose of this study, features which have been shown to hold a high discriminant value have been adopted. A history of some bowel abnormality is common and diarrhoea or rectal bleeding alone are of little diagnostic value. Baron et al (1964) performed careful correlations of sigmoidoscopic appearances between different trained observers, and found that contact and spontaneous bleeding ahead of the sigmoidoscope on an abnormal mucosa showed a high degree of consistency whereas abnormalities of colour, granularity, and excess mucus showed poor correlation.

Because of the difficulty of distinguishing histological changes in mild or quiescent colitis from the range of appearances seen in normal subjects (Flick, Voegtlin, and Rubin, 1962) care was taken, in the manner described above, to eliminate observer bias and to ensure that the results were reproducible. If these measures had not been taken it would not have been possible to make a confident diagnosis of colitis in two cases where the only abnormality was the presence of plasma cells in the lamina propria in excess of normal numbers (Fig. 1). In the three other cases diagnosed the histological changes were slight or moderate but there was infiltration by neutrophil polymorphonuclear leucocytes, a clear and absolute indication of inflammation (Fig. 2). More florid changes such as ulceration, erosion, or crypt abscesses were never seen.

Considerable difficulty can exist in the interpretation of barium enemas from patients with early ulcerative colitis. De Dombal, Geffen, Darnborough, Watkinson, and Goligher (1968) have shown that fine serrations are commonly found in the early stages of ulcerative colitis, and Fennessy et al (1966) reviewed the barium enemas of 292 patients with mild ulcerative colitis and defined the characteristics found in early disease. These criteria were adopted for the purposes of the present study.

The prevalence of ulcerative colitis of $17 \%$ in patients with ankylosing spondylitis in this series compares favourably with that of $18 \%$ found by Jayson and Bouchier (1968) in another series of patients studied by similar techniques, but without rectal histology. However, these authors 


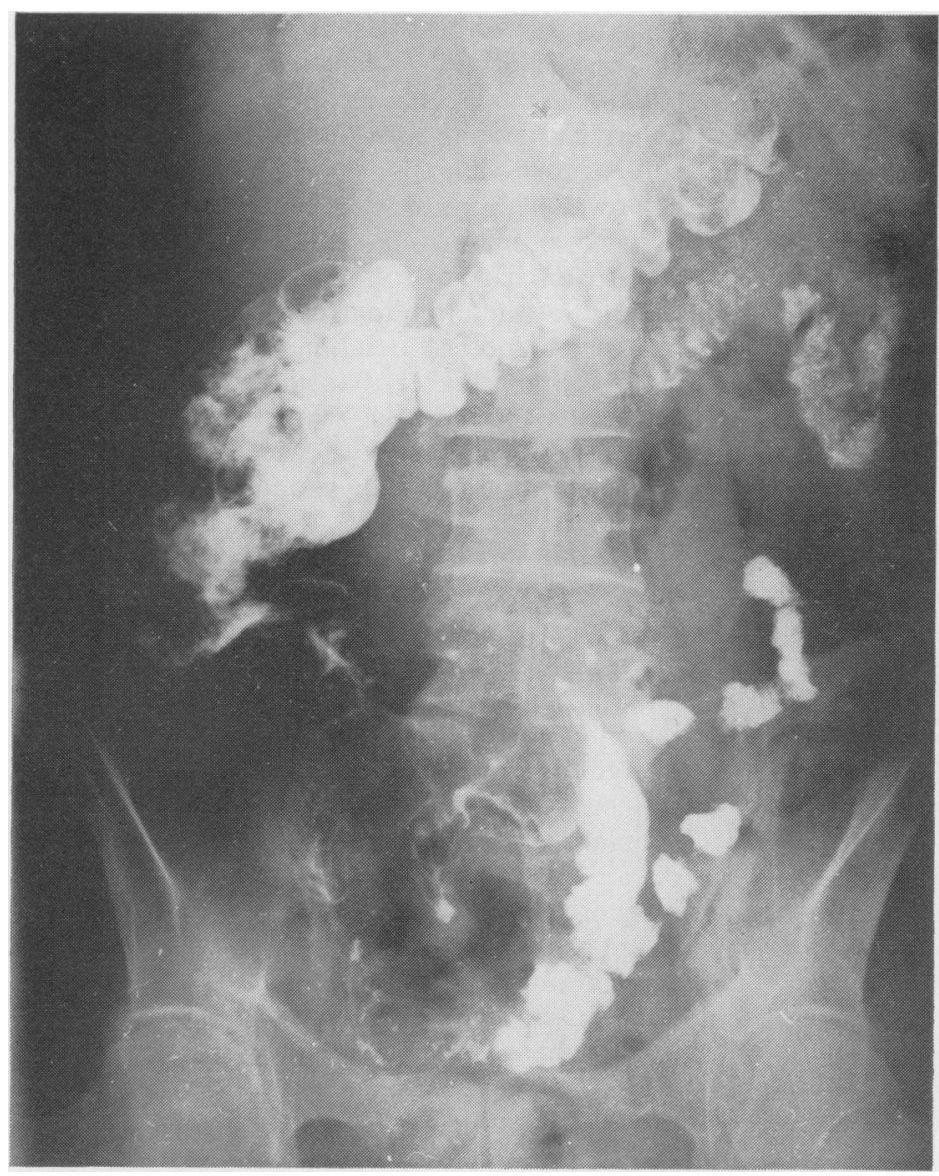

Fig. 5 Barium meal follow-through. A four and a half-hour film showing several large rounded filling defects in the terminal ileum. Normal caecal filling was not obtained, suggesting that this region was also involved.

found routine barium enema examination to be particularly helpful in the diagnosis of mild ulcerative colitis whereas in this study radiological examination contributed towards the diagnosis in only three cases. In other series in which investigations were restricted to those patients with bowel symptoms the prevalence of ulcerative colitis has been reported as up to $3.9 \%$ (Romanus, 1953; Steinberg and Storey, 1957; Wilkinson and Bywaters, 1958; McBride et al, 1963; and Serre and Simon, 1964). Jayson and Bouchier (1968) found a significantly longer history of spondylitis in those patients who also had ulcerative colitis but in the present study, although the mean length of history was longer in the colitic group, the difference was not significant.

Only 47 of 81 patients in whom the diagnosis of ankylosing spondylitis had been recorded attended for bowel investigations. Patients with intestinal symptoms are more likely to volunteer for this type of study and this may introduce an element of bias, increasing the apparent prevalence of the disease. If one assumes that all the patients with bowel symptoms would volunteer and that the symptom-free colitics were randomly distributed, the prevalence is $12.5 \%$ and the true prevalence rate lies between $12.5 \%$ and $17.0 \%$.

The cause of ankylosing spondylitis is not known but it may develop as a result of pelvic inflammation due to toxic substances entering the basivertebral venous system causing chronic recurrent inflammation of the spine. Chronic inflammatory bowel disease may cause ankylosing spondylitis by this mechanism. Spondylitis has similarly been reported in close association with many other types of chronic pelvic inflammation. Romanus (1953) found evidence of prostatis in 112 out of 114 cases, and Mason, Murray, Oates, and Young (1958) found evidence of chronic prostatitis in $83 \%$ of patients with ankylosing spondylitis compared with $33 \%$ of rheumatoid arthritics. Anti-prostate antibodies were found by Grimble and Lessof (1965) in 18 of 46 patients with ankylosing spondylitis and in only five of 169 cases with rheumatoid arthritis. Acheson (1960) found that $3 \%$ of patients with regional enteritis also had ankylosing spondylitis and 18 spondylitics were found by Kelly and Weisiger (1963) from case reports of 95 patients with Whipple's disease.

Seven of our ankylosing spondylitics gave a history of urogenital tract inflammation, and it is possible that further patients may have had chronic pelvic sepsis which was not suspected clinically.

The various analgesic and anti-inflammatory drugs used and radiotherapy applied to the spine might all affect the large bowel causing inflammatory changes. However, there were no differences in treatment between the colitic and noncolitic groups, suggesting that these factors did not play an important part in the development of bowel changes.

We should like to thank Drs J. A. Cosh, A. St. J. Dixon, and G. D. Kersley for allowing us to examine their patients, and Drs G. Ellison, M. McNulty, E. W. Moore, C. D. Thomson, and the late Dr H. J. Johnson of the United Bath Hospitals, and Dr J. Roylance of the Bristol Royal Infirmary for performing the barium enemas. We should also like to thank Drs I. Bouchier of the Royal Free Hospital, and K. Lumsden and S. C. Truelove of the Radcliffe Infirmary, Oxford, for interpreting the radiographs.

One of us (M.I.V.J.) is in receipt of a grant from the Medical Research Council.

\section{References}

Acheson, E. D. (1960). An association between ulcerative colitis, regional enteritis and ankylosing spondylitis. Quart. $J$. Med., 29, 489-499.

Baron, J. H., Connell, A. M., and Lennard-Jones, J. E. (1964) Variation between observers in describing mucosal appearances in proctocolitis. Brit. med. J., 1, 89-92. 
Bywaters, E. G. L., and Ansell, B. M. (1958). Arthritis associated with ulcerative colitis. Ann. rheum. Dis., 17, 169-183.

Court-Brown, W. M., and Doll, R. (1957). Leukaemia and aplastic anaemia in patients irradiated for ankylosing spondylitis. Spec. Rep. Ser. med. Res. Coun. (Lond.), 295, 1-135.

Dombal, F. T. de, Geffen, N., Darnborough, A., Watkinson, G., and Goligher, J. C. (1968). Radiological appearances of ulcerative colitis: an evaluation of their clinical significance. Gut, 9, 157-163.

Dick, A. P., Holt, L. P., and Dalton, E. R. (1966). Persistence of mucosal abnormality in ulcerative colitis. Gut, 7, 355-360.

Fennessy, J. J., Sparberg, M., and Kirsner, J. B. (1966). Early Roentgen manifestations of mild ulcerative colitis and proctitis. Radiology, 87, 848-858.

Fernandez-Herlihy, L. (1959). The articular manifestations of chronic ulcerative colitis. New Engl. J. Med., 261, 259-263.

Flick, A. L., Voegtlin, K. F., and Rubin, C. E. (1962). Clinical experience with suction biopsy of the rectal mucosa. Gastroenterology, 42, 691-705.

Ford, D. K., and Vallis, D. G. (1959). The clinical course of arthritis associated with ulcerative colitis and regional ileitis. Arthr. and Rheum., 2, 526-536.

Grimble, A., and Lessof, M. H. (1965). Anti-prostate antibodies in arthritis. Brit. med. J., 2, 263-264.

Jayson, M. I. V., and Bouchier, I. A. D. (1968). Ulcerative colitis with ankylosing spondylitis. Ann. rheum. Dis., 27, 219-224.

Kellgren, J. H. (1962). Diagnostic criteria for population studies. Bull. rheum. Dis., 13, 291-292.

Kelly, J. J., and Weisiger, B. B. (1963). The arthritis of Whipple's disease. Arthr. and Rheum., 6, 615-632.
Kiefer, E. D., and Gialanella, R. R. (1960). Arrested chronic ulcerative colitis. Gastroenterology, 39, 687-689.

Mason, R. M., Murray, R. S., Oates, J. K., and Young, A. C. (1958). Prostatitis and ankylosing spondylitis. Brit. med. J., 1, 748-751.

McBride, J. A., King, M. J., Baikie, A. G., Crean, G. P., and Sircus, W. (1963). Ankylosing spondylitis and chronic inflammatory disease of the intestine. Brit. med. J., 2 , 483-486.

McEwen, C., Lingg, C., Kirsner, J. B., and Spencer, J. A. (1962). Arthritis accompanying ulcerative colitis. Amer. J. Med., 33, 923-941.

Romanus, P. (1953). Pelvo-spondylitis ossificans in the male and genito-urinary infection. Acta med. scand., Suppl., 145, 280.

Rotstein, J., Entel, I., and Zeviner, B. (1963). Arthritis associated with ulcerative colitis. Ann. rheum. Dis., 22, 194-197.

Serre, H., and Simon, L. (1964). Rheumatoid spondylitis and ulcerative colitis. Rheumatism, 20, 13-16.

Steinberg, V. L., and Storey, G. (1957). Ankylosing spondylitis and chronic inflammatory lesions of the intestines. Brit. med. J., 2, 1157-1159.

Wilkinson, M., and Bywaters, E. G. L. (1958). Clinical features and course of ankylosing spondylitis. Ann. rheum. Dis., 17, 209-228.

Wright, R., Lumsden, K., Luntz, M. H., Sevel, D., and Truelove, S. C. (1965). Abnormalities of the sacro-iliac joints and uveitis in ulcerative colitis. Quart. J. Med., 34, 229-236.

Wright, V., and Watkinson, G. (1965). Sacro-iliitis and ulcerative colitis. Brit. med. J., 2, 675-680.

Zvaifler, N. J., and Martel, W. (1960). Spondylitis in chronic ulcerative colitis. Arthr. and Rheum., 3, 76-87. 